OCULAR INJURIES IN AUTOMOBILE CRASHES

Report Number UM-HSRI-80-22

by

Donald F. Huelke

and

James 0'Day

Highway Safety Research Institute

The University of Michigan

Ann Arbor, Michigan 48109

\author{
April 1980 \\ Prepared under Contract DOT-HS-8-01944 \\ National Highway Traffic Safety Administration \\ Department of Transportation \\ Washington, D.C.
}


Techaical Report Documentation Page

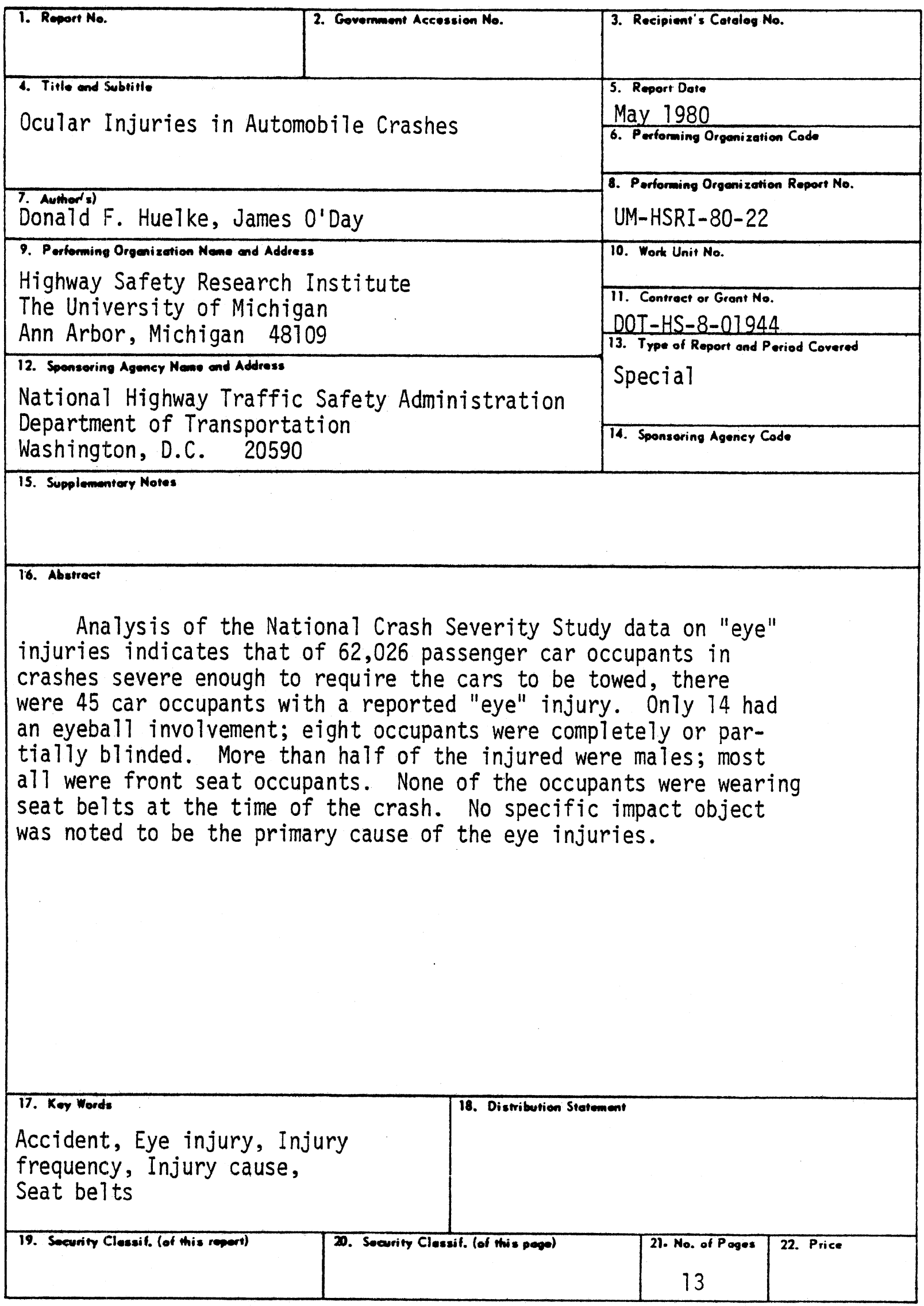


INTRODUCTION

Injuries to the eye and periorbital structures in automobile crashes have never been documented as to injury type and mechanism of injury, i.e., the specific object impacted within the car. Clinical records themselves generally do not contain information on the injury mechanism, and a review of hospital records cannot be used to determine national estimates of the more serious ocular injuries, i.e., blindness.

Only recently has a nationwide statistical sampling program collecting data on automobile crashes been established to sample occupant injuries and the causes of such injuries. This, the National Crash Severity Study (NCSS) is a major accident data collection program of the National Center for Statistics and Analysis (NCSA) of the National Highway Traffic Safety Administration (NHTSA). Field investigators collect detailed information on passenger cars, and the occupants, in crashes which were severe enough to disable the car. Excluded are crashes involving only trucks, motorcycles, buses, or pedestrians, and passenger cars not towed from the scene.

The data contain information on the vehicle damage in a codified form, on the instantaneous change of velocity during the impact phase of the crash, and descriptions of the occupant injuries and injury contact areas. Information on other vehicles involved in these accidents (trucks, or non-towed passenger cars which were in crashes with towed passenger cars) is included in the data, but is used only to describe the crash conditions surrounding the vehicle of interest. Data collection began in January, 1977, and the data available for this study cover the period from January 1977 through March, 1977. Crashes are selected by strict adherence to a stratified sampling plan. Accidents eligible for investigation are all police-reported accidents within defined geographical areas in which at least one occupied passenger automobile was towed from the scene due to collision damage. Towed passenger cars and their occupants constitute the population under study. 


\section{INJURY CODING}

The Abbreviated Injury Scale (AIS) is used in the NCSS file to appropriately categorize the severity of injury (2). Most all periorbital or ocular injuries are at either of the minor (AIS-1) or moderate (AIS-2) level. The only severe (AIS-3) "eye" injury would be optic nerve avulsion. ${ }^{1}$

One of the body areas which can be identified in the injury classification scheme used in this study is the eye(1). All cases involving eye injuries coded as greater than "minor" on the injury reporting scale (2) were retrieved by computer search. There were 45 persons who had reported "eye" injuries of moderate or greater severity. The original detailed investigation reports were obtained for each of these and reviewed. Of the 45 occupants, two were killed, each having massive head/orbital injuries. These two individuals will be omitted from the analysis.

DATA ANALYSIS

Twenty-five of the 43 surviving eye-injured occupants were drivers (13 males, 12 females), 12 were front-right passengers, and 6 were the rear seat occupants. Approximately three out of four injured occupants were 25 years of age or younger. As might be expected, most of the injuries were lacerations of the periorbital structures. None of these injured occupants were wearing seat belts. A summary of the eye injuries and the impact object to which the injury was attributed are presented in Table 1.

There were 14 passenger car occupants who sustained injuries to the eyeball or its musculature (Table 2). Five of these were completely blinded in one eye and three were partially blinded. One other person had eyeball muscle paralysis.

The impact areas related to the injuries is shown in Table 3 . Note that for the 29 occupants without ocular involvement at least 16 were injured by contact with the windshield. No other single car structure

${ }^{1}$ The Abbreviated Injury Scale: 0-No injury, 1-Minor, 2-Moderate, 3 Severe, 4-Serious, 5-Critical to 1 ife, 6-Currently unsurvivable. 


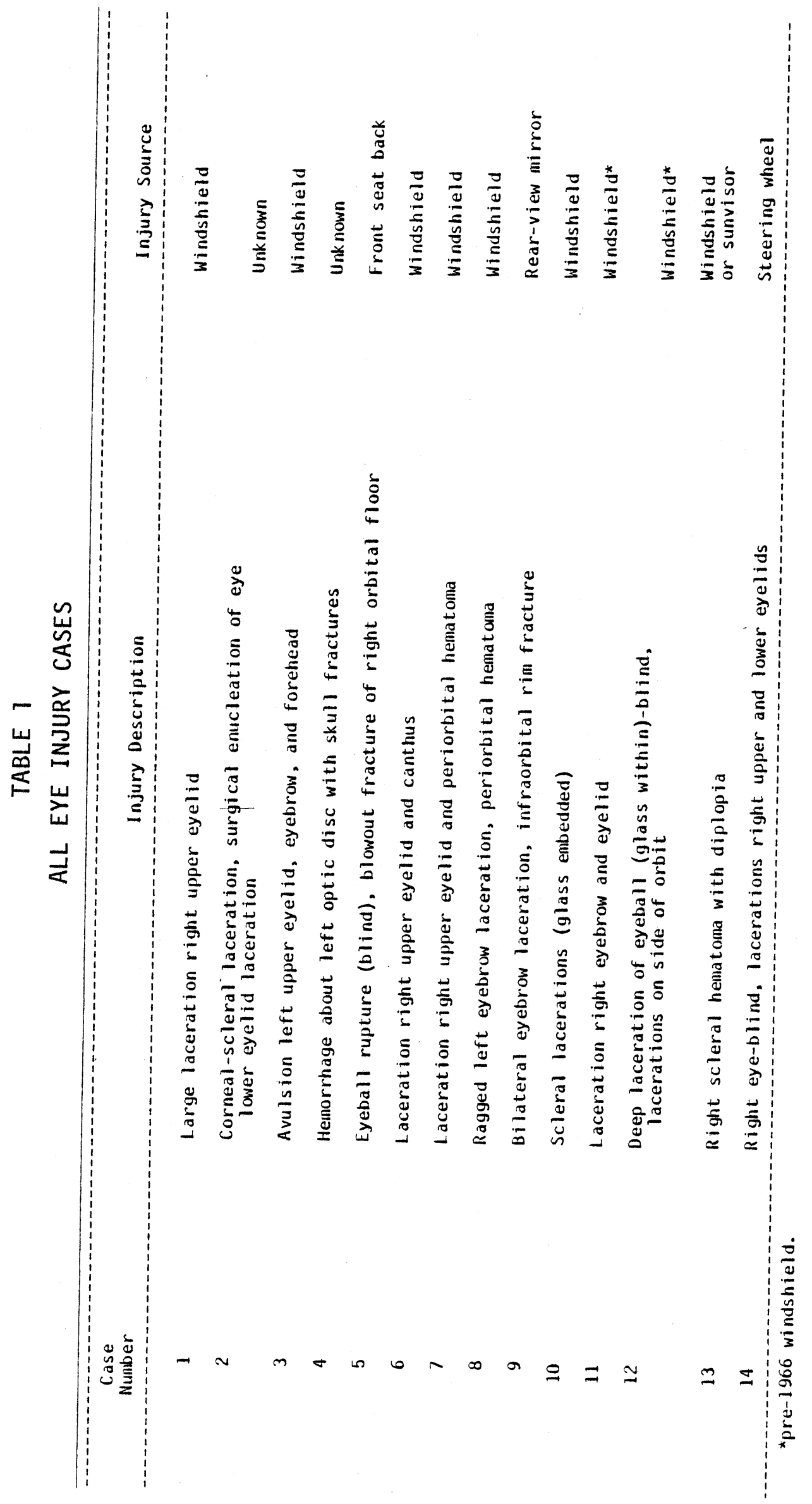




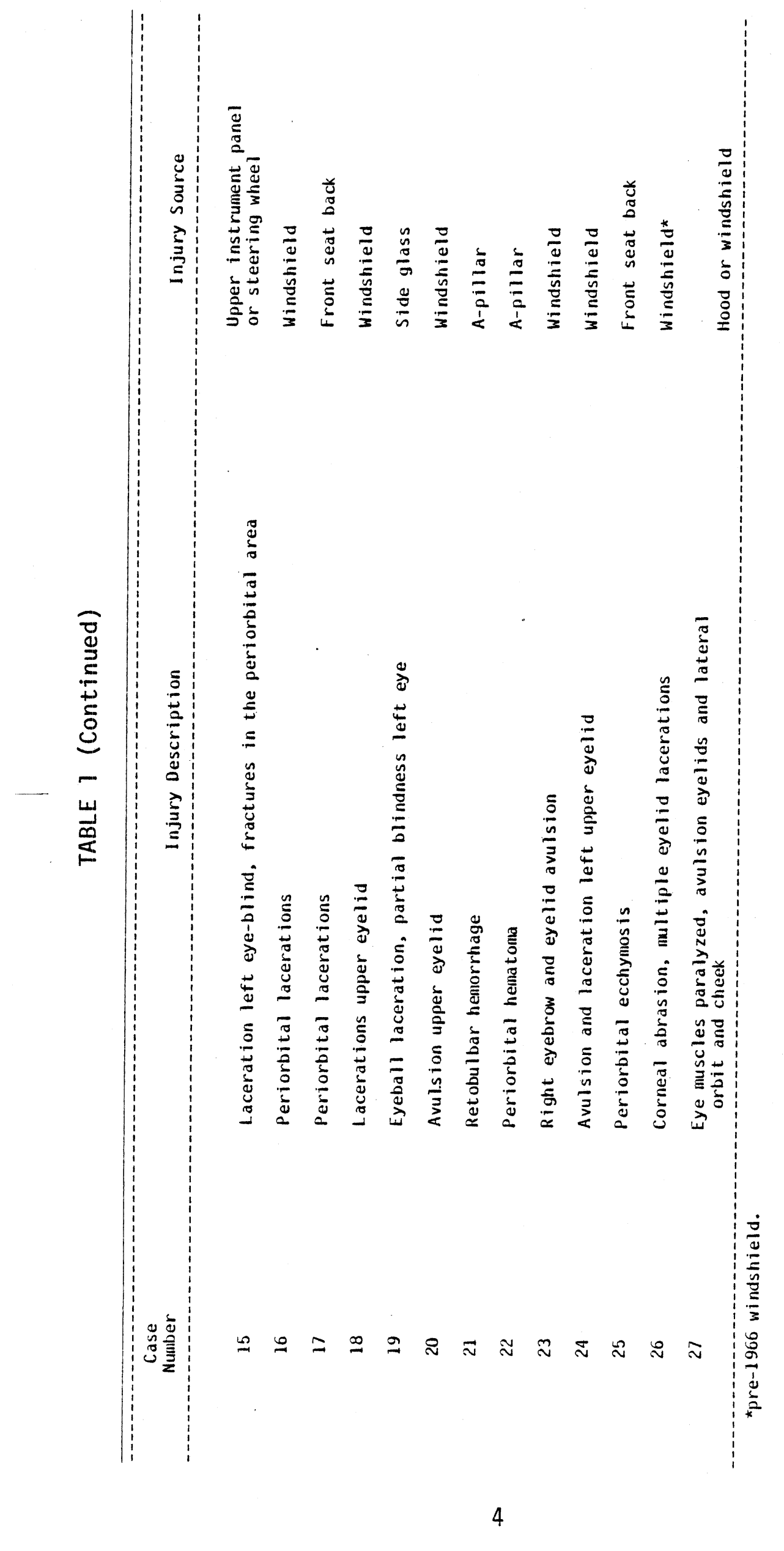




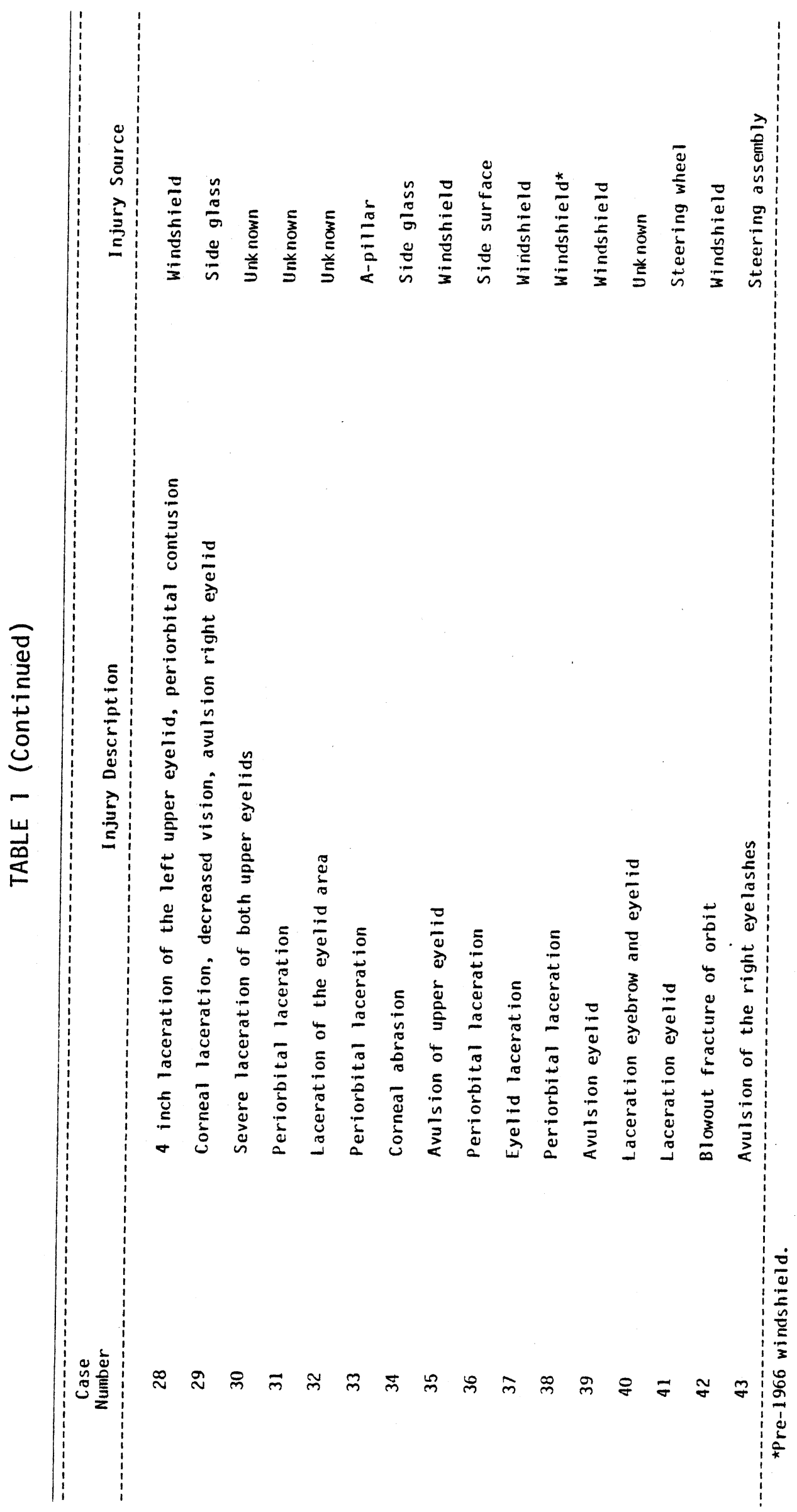




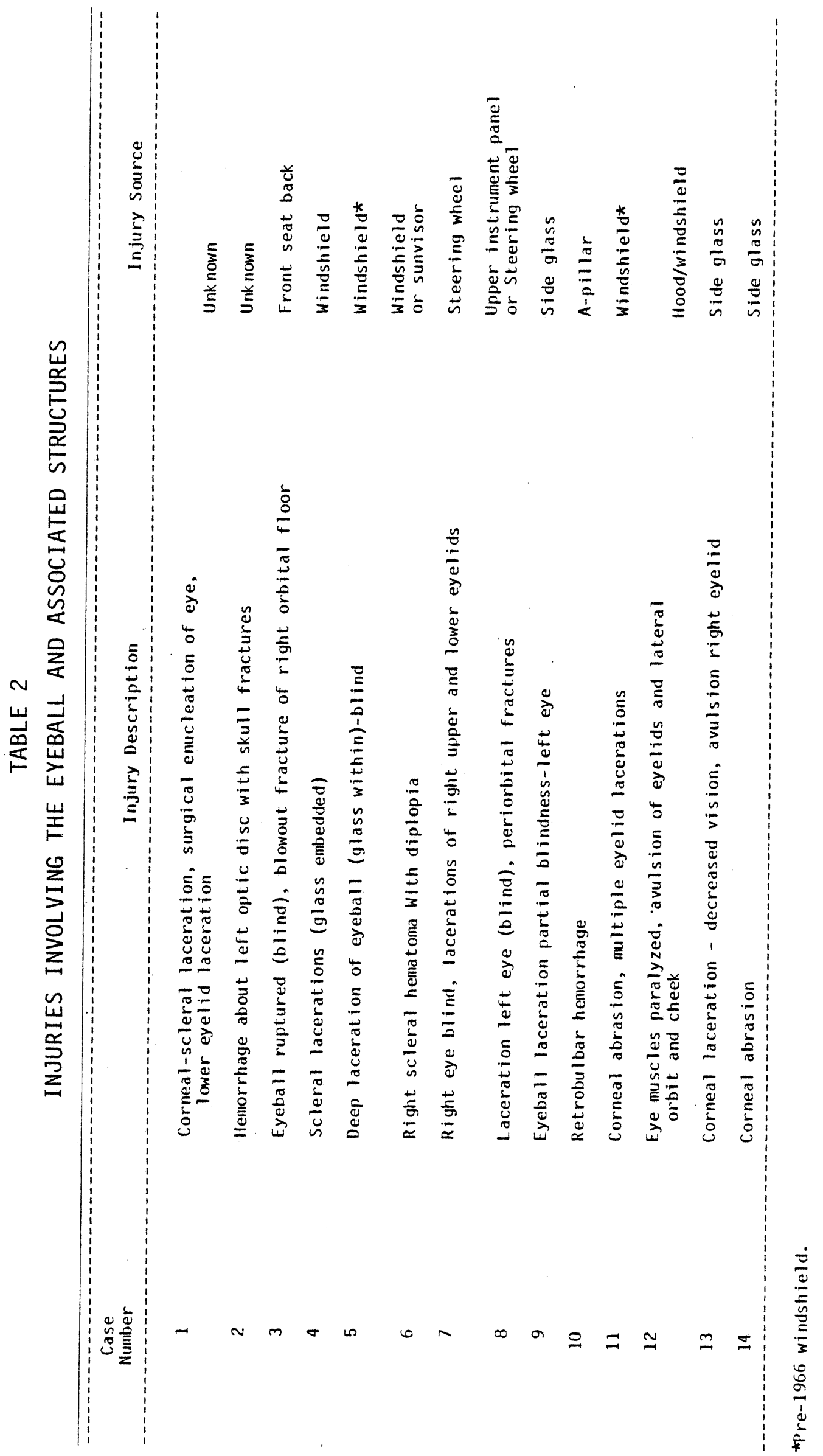


was so highly involved. However, when the globe itself was injured (14 occupants), no single injury-producing object stood out as the most common, although there were two injuries attributed to the side glass and three to the pre-1966 windshield.

TABLE 3

CONTACT AREAS RELATED TO ORBITAL/PERIORBITAL INJURIES

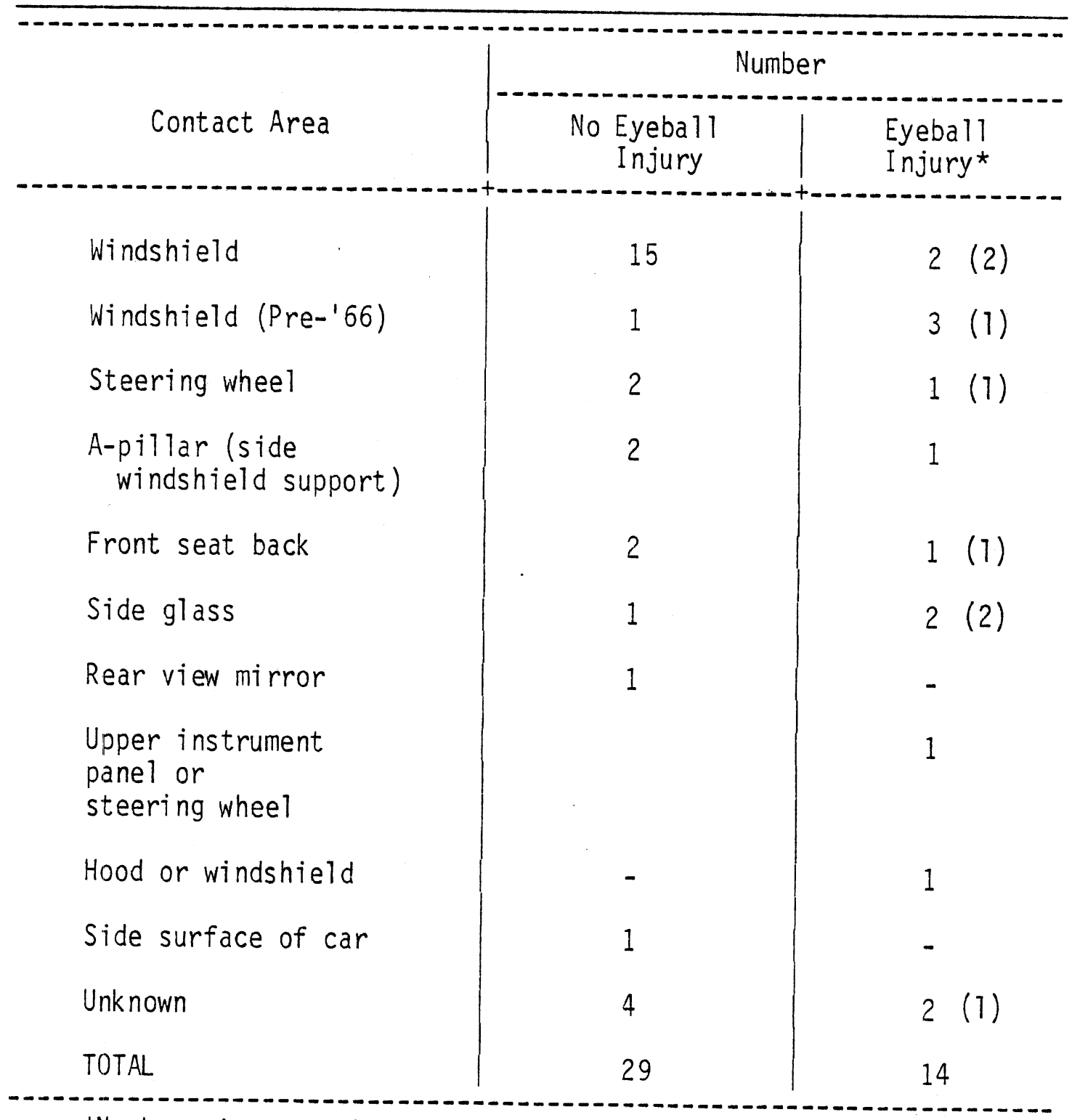

* Numbers in parentheses are individuals with partial or complete blindness in one eye. 
The total NCSS data (for the fifteen month period) represent approximately 62,000 occupants of towed passenger cars. The eight cases of the more serious eye injuries, i.e., blindness in one eye (5), partial blindness in one eye (2), and eye muscle paralysis (1), all occurred in crashes sampled at the $100 \%$ rate, and thus a first estimate of the relative frequency of permanent eye impairment might be based on this ratio: 8/62,000. Approximately one-third of the persons in the NCSS data have injuries listed as "unknown"--i.e., detailed medical reports for these persons were not available. It is not possible to determine whether the incidence of eye problems in this group was the same or different from those actually determined.

To account for the one-third missing data, the eight cases may be multiplied by 1.5--yielding an estimate of 12 cases of permanent eye impaiment ( 7.5 blind in one eye) among the 62,000 .

The number of cases of complete blindness in one eye is so small that extrapolation to a national population is hazardous. For the areas sampled, the time period of the study was 15 months. An annual estimate for these areas may be computed by multiplying the above numbers by $12 / 15$ thus yielding six cases of blindness in one eye annually or 9.6 total eye-impaired car occupants. These numbers are so smal1--i.e., permanent ocular damage in these crashes is so rare--that it would not be appropriate to attempt a national projection. A second year of NCSS data, and the upcoming National Accident Severity Study data will add significantly to the data base and should ultimately lead to a defensible national estimate. ${ }^{2}$

DISCUSSION

Beginning with the 1966 models, the windshield construction of United States manufactured cars was of a "new type"--a High Penetration Resistant (HPR) windshield. This improved laminated windshield markedly reduces head penetration through the glass, and decreases the extensive,

${ }^{2}$ Data for the last 12 months of the NCSS became available late in this study of ocular injuries, and have not been included in the statistics presented. We note, however, that there is a somewhat lower incidence of eyeball injury in the later data, and that the total numbers are still inadequate for making national estimates. 
disfiguring facial lacerations previously seen from windshield impacts (3-7). In that more than half of the automobile crashes are frontal collisions, it is not surprising that the windshield would be most often involved with periorbital or ocular injuries for the non-seat belted front seat occupant.

In England and Europe many of the cars have tempered windshields. When impacted, this glass breaks into small pieces but not infrequently the occupant's face contacts the jagged glass retained in the lower windshield frame, the main cause of ocular perforations (8). Mackay (England) indicated that of seriously injured front seat occupants $3-5 \%$ have an eye injury with perhaps 1800 car occupants receiving serious injuries in Britain each year. At least $70 \%$ of these injuries can be attributed to the tempered windscreens (9). A review of Mackay's excellent summary of the eye injury literature indicates that most authors agree that eyeball injury is highly related to the tempered windshield that has been typical of cars in Europe, England, Australia, and Asian countries (8). Most authors agree that lap-shoulder belts will decrease the frequency of eyeball injuries (8), and many have suggested laminated glass for the windshield (8). Langwieder (Germany) found only one eye injury from the HPR laminated glass (out of 228 occupants with head injury), and 17 eye injury cases from tempered glass (of 545 head injuries), a nine-fold increase in cars with tempered windshields (10).

Holland estimated about 1,000 people per year (1970) sustain severe eye/eyelid injuries from road accidents in the Federal Republic of Germany. In about $25 \%$ of these cases, or about 250 people, the injuries lead to almost complete loss of vision for one eye, and for a smaller group it results in a loss of both eyes (11). It has been estimated that blindness of one or both eyes occurs to 2,500 people each year in Europe (12).

CONCLUSIONS

Tempered windshields commonly used in Europe have been shown to be highly related to ocular injuries. Although windshields of the HPR type in cars in North America are not at all significantly involved in ocular injuries still, about $50 \%$ of the injuries of the eye area are caused by 
glass. The HPR windshield probably is the main reason for the relatively low occurrence of ocular injuries in United States crashes compared to these injuries reported from countries with tempered windshields.

No ocular injuries were observed among belted occupants in this study. Increased use of lap-shoulder belts would decrease the likelihood for occupant contact with the windshield, mirrors, A-Pillar, steering column and instrument panel--about half of the occupant contacts for ocular injury--and thus further reduce the incidence of injuries leading to decreased vision.

Data from the first fifteen months of the NCSS program provide an estimate of 7.5 cases of blindness in one eye among 62,000 occupants of passenger cars damaged severely enough to require towing from the scene. 


\section{REFERENCES}

(1) Marsh, J. C. "An Occupant Injury Classification Procedure Incorporating the Abbreviated Injury Scale," NATO Committee on the Challenges of Modern Society, Road Safety Pilot Study, Brussels, June 1973.

(2) "The Abbreviated Injury Scale: History, Growth, and Future," Trans., Nat. Safety Congress, School and College Conference, Chicago, Oct. 15, 1979.

(3) Huelke, D.F., Grabb, W. C., and Dingman, R. 0., "Facial Injuries in Automobile Accidents." Proceedings, American Association for Automotive Medicine, Louisville, Oct. 1964.

(4) Huelke, D. F., Grabb, W. C., and Gikas, P. W., "Injuries and Deaths From Windshield and Instrument Panel Impacts," Proceedings, Eighth Stapp Car Crash Conference, Detroit, Oct. 1964. Wayne State University Press, Detroit, Michigan, pp. 167-184, 1966 .

(5) Huelke, D. F., Grabb, W. C., and Dingman, R. 0., "Facial Injuries Due to Windshield Impacts in Automobile Accidents." J. Plast. and Reconst. Surg., 37:324-333, 1966.

(6) Huelke, D. F., Grabb, W. C., and Dingman, R. O., "Automobile Occupant Injuries From Striking The Windshield." Highway Safety Research Institute, The University of Michigan, Ann Arbor. HSRI Report No. Bio-5, 1967.

(7) Huelke, D. F., Grabb, W. C., Dingman, R. O., and Oneal, R. M., "The New Automobile Windshield and Its Effectiveness in Reducing Facial Lacerations." J. Plast. and Reconst. Surg., 41(6):554-559, 1968 .

(8) Mackay, G. M., "Injuries from Windscreens. A Review of Some Recent Literature." A report to the Commission of the E.E.C.; Feb., 1978.

(9) Mackay, G. M., "Incidence of Trauma to the Eyes of Car Occupants." Trans. Ophthal. Soc. of the United Kingdom, Vol. XCV, Part II, pp. 311-314, 1975 .

(10) Langwieder, K., "Interior Safety of Automobiles." Proceedings, Third International Tech. Conference on Experimental Safety Vehicles. pp. 2-217-220, Washington, D.C., 1972.

(11) Holland, G., "Eye and Eyelid Injuries from Windshields and Means to Prevent Them." 1970 International Automobile Safety Conference Compendium, pp. 1187-1194, SAE, 1970.

(12) Windshield Symposium on Eye Injuries: XIIIth FISITA Congress, International Automobile Safety Conference, Brussels, 1970. 